\title{
Visualization of Research Hotspots in Teacher-Student Relations in China from 2004 to 2018: Knowledge Mapping Analysis
}

\author{
Xiaotao Lu \\ College of Education Science, Gannan Normal University, Ganzhou, China \\ Email: LJY19933@126.com
}

How to cite this paper: Lu, X.T. (2019) Visualization of Research Hotspots in Teacher-Student Relations in China from 2004 to 2018: Knowledge Mapping Analysis. Open Access Library Journal, 6: e5752. https://doi.org/10.4236/oalib.1105752

Received: September 2, 2019

Accepted: September 17, 2019

Published: September 20, 2019

Copyright () 2019 by author(s) and Open Access Library Inc.

This work is licensed under the Creative Commons Attribution International License (CC BY 4.0).

http://creativecommons.org/licenses/by/4.0/

\begin{abstract}
To objectively and accurately understand the hotspots and trends of the research on teacher-student relationship in China in the past 15 years. Using the two softwares Bicomb 2.01 and SPSS 19.0, Keyword Co-word Analysis, Cluster Analysis and Multidimensional Scale Analysis were performed on 322 CSSCI journal articles retrieved from China National Knowledge Infrastructure and the time limit is 2004 to 2018. And last drawing the Hotspots Knowledge Mapping of research on teacher-student relationship. The results show that the research hotspots of teacher-student relationship in China in the past 15 years mainly focus on two main lines and four major fields. The two main lines are theoretical research and quantitative research on teacher-student relationship, including four research fields: 1) Theoretical research and cognition of teacher-student relations; 2) The relationship between teacher-student relationship and student learning; 3) Alienation and reconstruction of postgraduate teacher-student relations; 4) Research on harmonious teacher-student relations in ideological and political theory course for college students.
\end{abstract}

\section{Subject Areas}

Education

\section{Keywords}

Teacher-Student Relationship, Research Hotspots, Knowledge Mapping

\section{Introduction}

Teacher-student relationship is a timeless topic. As the most fundamental and 
core component of the relations constitute, it's good or not directly determines the quality of education, teaching efficiency and the healthy growth of teachers and students. Through reading the modern history of foreign education, it can be found that the research of teacher-student relationship has been centered on "student-centered" or "teacher-centered"? Johann Friedrich Herbart, a representative of the traditional education school, 19th century German philosopher, psychologist and founder of scientific education, put forward the idea of "teacher-centered", arguing that teachers are the center of the teaching process and students are the dominators in teaching. While the representative of practical education theory, American philosophers, educators, and pragmatic masters, John Dewey puts forward "student-centered" and advocates the development of students' personality with children's physical and mental laws. Subsequently, with the continuous development of educational theory, different educational schools also have different opinions on the relationship between teachers and students, such as emphasizing the equality between teachers and students, dialogue, understanding and trust, etc.

In terms of quantitative research, scholars in educational sociology, educational psychology and other fields have conducted a large number of researches on teacher-student relationship, focusing on the influence factors, operation mode and way of teacher-student relationship. American scholar H. J. Leavitt proposed the small group communication mode, which was divided into four types: circle type, chain type, word type and wheel type [1]. J. W. Getzls and H. A. Thelen believes that human behavior emerges from and is influenced by social system factors, and that teachers' leadership styles and role conflicts in teaching are influenced by group norms and individual traits [2]. B. J. Ashley divides teacher-student relationship into three types: teacher-centered, textbook centered and student-centered [3]. Chinese scholars Yang, J. P. and Gao, L. (2005) believe that teacher-student relationship has a significant impact on pupils' learning psychology and can predict pupils' academic achievements [4]. Chinese scholars Ma, L., Jiang, P. P. and Yang, R. (2017) believe that teacher-student relationship is highly correlated with college students' learning engagement [5]. Yu, X. M., Zhao, J. R. and Wu, X. (2017) believe that teacher-student relationship has a significant impact on the scientific research performance of graduate students, and is an important factor affecting the scientific research performance of graduate students [6].

Other literature reviews of teacher-student relations focus on the connotation, characteristics, types, influencing factors and construction of teacher-student relations. In this review, we use scientometrics method to link key words with and sentences through the co-word analysis technique from the perspective of map of scientific knowledge to reveal the current research fields and developments in teacher-student relationship, so as to provide reference for relevant scholars and research fields.

This paper conducts Knowledge Mapping Analysis on 334 literatures published in professional journals from 2004 to 2018. 
The data retrieval scope of this study was China National Knowledge Infrastructure (CNKI) database, and it was included in Chinese Social Sciences Citation Index (CSSCI). This study aims to explore the following questions:

- Q1: What is the overall bibliometric data extracted from the teacher-student relationship literature?

- Q2: what are the hot topics in the research of teacher-student relationship?

\section{Research Design}

\subsection{Resource Source}

First, find the information. On August 10, 2019, the author entered the "advanced search" function of CNKI search database, and set the retrieve text name "teacher-student relationship" under the state of "journal", and the search time was "2004-2018", and the source category was CSSCI. A total of 334 research literatures and various materials were searched. Secondly, determine the research data. A total of 322 valid literatures were obtained after manual screening and elimination of 12 unqualified literatures, such as "book review", "no keywords", "no author information", "conference review" and "repeated literatures", etc. Finally, specification data. To standardize the processing of keywords, such as the unification of "inter-subject" and "inter-subjectivity" into "intersubjectivity".

\subsection{Research Tools}

In this study, Bibliographic Items co-occurrence Matrix Builder (Bicomb 2.01 version) [7] and Statistical Product and Service Solutions (IBM SPSS 19.0 version), jointly developed by the department of medical information Professor Cui, L. and Shenyang Hongsheng Computer Technology CO. LTD of China medical university, were selected as the main research tools.

\subsection{Research Design Process}

Firstly, choose research datas. Relevant literatures were retrieved and initial data were screened and preprocessed. Secondly, the year, keywords, journal name, author and research institution were extracted through Bicomb 2.01. Thirdly, high frequency keywords are processed in Bicomb 2.01 software to derive the lexical matrix. Fourthly, the lexical matrix is processed by using the system cluster analysis function of SPSS 19.0, and the tree graph and similarity matrix are derived. Fifthly, SPSS 19.0 multi-dimensional scale analysis function is used to generate Euclidean distance model graph and form strategic coordinate graph of high-frequency keywords. Finally, the systematic clustering dendrogram and multidimensional scale map are combined to perform semantic analysis and content interpretation to reveal the hotspots of teacher-student relationship research.

\section{Research Results and Analysis}

Through Bicomb 2.01 software, time distribution statistics, author unit distribu- 
tion statistics, journal paper distribution statistics, high frequency keyword frequency statistics, etc. were provided for 322 teacher-student relationship research papers, providing data support and research for the status and characteristics of teacher-student relationship research basis.

\subsection{Time Distribution Statistics of Papers}

According to the statistical function of Bicomb 2.01, the teacher-student relationship research shows a "fluctuating" development trend, as shown in Figure 1.

\subsection{Distribution Statistics of Paper Author Units}

According to the statistical function of Bicomb2.01 software, the author units of the research on teacher-student relationship mainly focus on Education Department, Educational Science College and Developmental Psychology Institute of normal university, while the proportion of other research institutions is obviously small, which shows that the educational research institutions of China's normal university are constantly committed to the research and exploration of teacher-student relationship, as shown in Table 1.

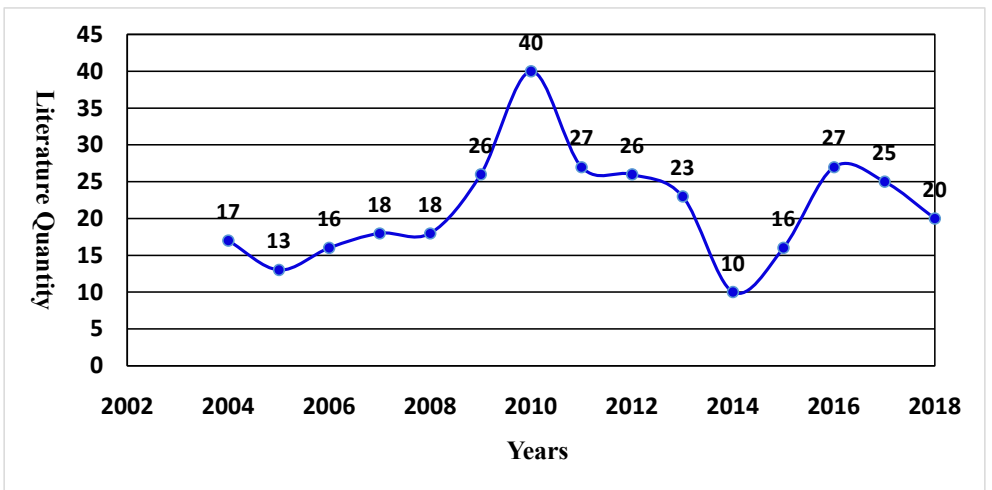

Figure 1. Annual distribution of sample size.

Table 1. Distribution of author units (Partial).

\begin{tabular}{ccc}
\hline Number & Author Units & $\begin{array}{c}\text { Frequency } \\
\text { (Times) }\end{array}$ \\
\hline 1 & Education Department of Beijing Normal University & 10 \\
2 & Developmental Psychology Institute of Beijing Normal University & 10 \\
3 & Educational Science College of Shanxi University & 8 \\
4 & Educational Science College of Hunan Normal University & 8 \\
5 & Educational Science College of Nanjing Normal University & 6 \\
6 & Education Department of Southwest University & 6 \\
7 & Education College of Liaoning Normal University & 5 \\
8 & Education College of Shaanxi Normal University & 5 \\
9 & Higher Education Development Research Center of Xiamen University & 4 \\
10 & Wuxi Institute of Arts and Technology & 4
\end{tabular}




\subsection{Distribution Statistics of Journal Publication Volume}

According to the statistical function of Bicomb 2.01 software, 322 research papers on teacher-student relationship come from 116 journals, among which the number of papers published more than 8 times is mainly concentrated in Theory and Practice of Education, Journal of the Chinese Society of Education, Heilongjiang Researches on Higher Education and so on, as shown in Table 2.

\subsection{Frequency Statistics of High Frequency Keywords}

After the key words in 322 literatures were counted by Bicomb 2.01 software, the key words were normalized. There were $715 \mathrm{key}$ words in total, with a total frequency of 1315 . Frequency $\geq 7$ was selected as the high-frequency words, and 20 key words were obtained, as shown in Table 3 . The cumulative frequency of occurrence of high-frequency keywords was 518 times, and the cumulative percentage was $39.39 \%$, which exceeded the $27 \%$ specified in knowledge mapping analysis and met the analysis requirements [8].

\subsection{Co-Word Matrix and Analysis of High Frequency Keywords}

Using Bicomb 2.01 software was carried out on the high frequency keywords co-word analysis, generated lexical matrix after import the SPSS 19.0, select ochiai coefficient is transformed into $20 \times 20$ similar matrix, such as Table 4 . Using Excel table, subtract the similarity matrix with "1" to get the dissimilarity matrix of two keywords' difference degree, as shown in Table 5.

Table 2. Volume of papers published in journals (Partial).

\begin{tabular}{ccc}
\hline Number & Journal Name & Frequency (Times) \\
\hline 1 & Theory and Practice of Education & 23 \\
2 & Journal of the Chinese Society of Education & 16 \\
3 & Heilongjiang Researches on Higher Education & 12 \\
4 & Education Science & 11 \\
5 & Cournal of Shanghai Educational Research & 9 \\
6 & Academic Degrees \& Graduate Education & 9 \\
7 & Ideological \& Theoretical Education & 9 \\
8 & University Education Science & 9 \\
10 & Jiangsu Higher Education & 8 \\
\hline
\end{tabular}

Table 3. Frequency statistics of high frequency keywords.

\begin{tabular}{cccc}
\hline Number & Keywords & $\begin{array}{c}\text { Frequency } \\
\text { (Times) }\end{array}$ & $\begin{array}{c}\text { Cumulative Percent } \\
\text { (\%) }\end{array}$ \\
\hline 1 & teacher-student relationship & 264 & 20.08 \\
2 & harmonious teacher-student relationship & 27 & 22.13 \\
3 & college teacher-student relationship & 26 & 24.11 \\
4 & interpersonal relationship & 22 & 25.78 \\
5 & intersubjectivity & 18 & 27.15 \\
\hline
\end{tabular}


X. T. Lu

\section{Continued}

\begin{tabular}{lcll}
\hline 6 & student learning & 17 & 28.44 \\
7 & dialogue & 16 & 29.66 \\
8 & primary and secondary school students & 16 & 30.87 \\
9 & refactoring & 15 & 32.02 \\
10 & contact & 11 & 32.85 \\
11 & postgraduate & 10 & 33.61 \\
12 & democratic equality & 10 & 34.37 \\
13 & knowledge-based view & 10 & 35.13 \\
14 & ideological and political theory course & 9 & 35.82 \\
15 & concern & 9 & 36.50 \\
16 & university student & 9 & 37.19 \\
17 & teacher & 8 & 37.79 \\
18 & subjectivity & 7 & 38.33 \\
19 & alienation & 7 & 38.86 \\
20 & understand & 7 & 39.39 \\
\hline
\end{tabular}

Table 4. High frequency keyword similarity matrix (Partial).

\begin{tabular}{|c|c|c|c|c|c|}
\hline $\begin{array}{l}\text { High Frequency } \\
\text { Keywords }\end{array}$ & $\begin{array}{l}\text { teacher-student } \\
\text { relationship }\end{array}$ & $\begin{array}{l}\text { harmonious } \\
\text { teacher-student } \\
\text { relationship }\end{array}$ & $\begin{array}{l}\text { college } \\
\text { teacher-student } \\
\text { relationship }\end{array}$ & $\begin{array}{l}\text { interpersonal } \\
\text { relationship }\end{array}$ & intersubjectivity \\
\hline $\begin{array}{l}\text { teacher-student } \\
\text { relationship }\end{array}$ & 1.000 & 0.109 & 0.133 & 0.270 & 0.189 \\
\hline $\begin{array}{l}\text { harmonious } \\
\text { teacher-student } \\
\text { relationship }\end{array}$ & 0.109 & 1.000 & 0.192 & 0.000 & 0.046 \\
\hline $\begin{array}{l}\text { college } \\
\text { teacher-student } \\
\text { relationship }\end{array}$ & 0.133 & 0.192 & 1.000 & 0.043 & 0.046 \\
\hline $\begin{array}{l}\text { interpersonal } \\
\text { relationship }\end{array}$ & 0.270 & 0.000 & 0.043 & 1.000 & 0.051 \\
\hline intersubjectivity & 0.189 & 0.046 & 0.046 & 0.051 & 1.000 \\
\hline
\end{tabular}

Table 5. High frequency keyword dissimilarity matrix (Partial).

\begin{tabular}{|c|c|c|c|c|c|}
\hline $\begin{array}{l}\text { High Frequency } \\
\text { Keywords }\end{array}$ & $\begin{array}{l}\text { teacher-student } \\
\text { relationship }\end{array}$ & $\begin{array}{l}\text { harmonious } \\
\text { teacher-student } \\
\text { relationship }\end{array}$ & $\begin{array}{l}\text { college } \\
\text { teacher-student } \\
\text { relationship }\end{array}$ & $\begin{array}{l}\text { interpersonal } \\
\text { relationship }\end{array}$ & intersubjectivity \\
\hline $\begin{array}{l}\text { teacher-student } \\
\text { relationship }\end{array}$ & 0.000 & 0.891 & 0.867 & 0.730 & 0.811 \\
\hline $\begin{array}{l}\text { harmonious } \\
\text { teacher-student } \\
\text { relationship }\end{array}$ & 0.891 & 0.000 & 0.808 & 1.000 & 0.954 \\
\hline $\begin{array}{l}\text { college } \\
\text { teacher-student } \\
\text { relationship }\end{array}$ & 0.867 & 0.808 & 0.000 & 0.957 & 0.954 \\
\hline $\begin{array}{l}\text { interpersonal } \\
\text { relationship }\end{array}$ & 0.730 & 1.000 & 0.957 & 0.000 & 0.949 \\
\hline intersubjectivity & 0.811 & 0.954 & 0.954 & 0.949 & 0.000 \\
\hline
\end{tabular}


The number size in Table 4 similarity matrix indicates the distance between keywords. The closer the value is to 1 , the closer the distance between keywords is, and the greater the similarity is. On the contrary, the closer the value is to 0 , the larger the distance between keywords, the smaller the similarity [9]. The keywords compared with A from close to far are: interpersonal relationship (0.270), intersubjectivity (0.189), college teacher-student relationship (0.133), harmonious teacher-student relationship (0.109), the similarity values of these high frequency keywords are relatively small. After analyzing the coefficient size in the table, it is found that "college teacher-student relationship" and "harmonious teacher-student relationship" are often together (distance $=0.024$ ); "intersubjectivity" and "college teacher-student relationship" are often present together (distance $=0.056$ ). This part of results analysis shows that in the existing research results of teacher-student relationship, some researchers have discussed the relationship between college teacher-student relationship, harmonious teacher-student relationship and intersubjectivity.

The value in Table 5 dissimilarity matrix is equal to or close to 0 , indicating that the two keywords are closer to each other and the correlation with the research topic is closer. On the contrary, the value is equal to or close to 1 , indicating that the two keywords are more distant from each other, deviating from the research topic or irrelevant.

\subsection{System Clustering Analysis of High Frequency Keywords}

Clustering analysis methodology can dig deeper into data (high frequency keywords). Taking the frequency (co-word) appearing in the same article as the analysis object, using cluster statistical method to mathematically statistics and analyze the distance between words and words in the co-word relationship, the keywords with close relationship (distance relatively close) are gathered together to form a relatively independent group [10]. Import the $20 \times 20$ lexical matrix generated by Bicomb 2.01 software into SPSS19.0 and systematically cluster analysis it, as shown in Figure 2. For the sake of explanation, we use Field 1 as an example. It should be noted that initially each keyword is a separate class. First, SPSS 19.0 software automatically calculates the similarity between No. 7 and No. 20, and aggregates into the same class. Secondly, it is the same class as No. 12, and so on. Finally, it merges with No. 13 into a large class. Therefore, through the structure of systematic clustering dendrogram, we can divide high frequency keywords into four areas: Field 1 composed of 7, 20, 12, 5, 18 and 13; Field 2 composed of 6, 8, 1, 4, 17 and 15; Field 3 composed of 11, 19 and 9; Field 4 composed of 14, 16, 2, 3 and 10. Through the high frequency keyword co-occurrence clustering analysis in the field of teacher-student relationship, we can objectively see the research hotspots in this field, but we can not see the position of each research hotspot in the research of teacher-student relationship. Therefore, we need to further analyze it through multidimensional scale. 


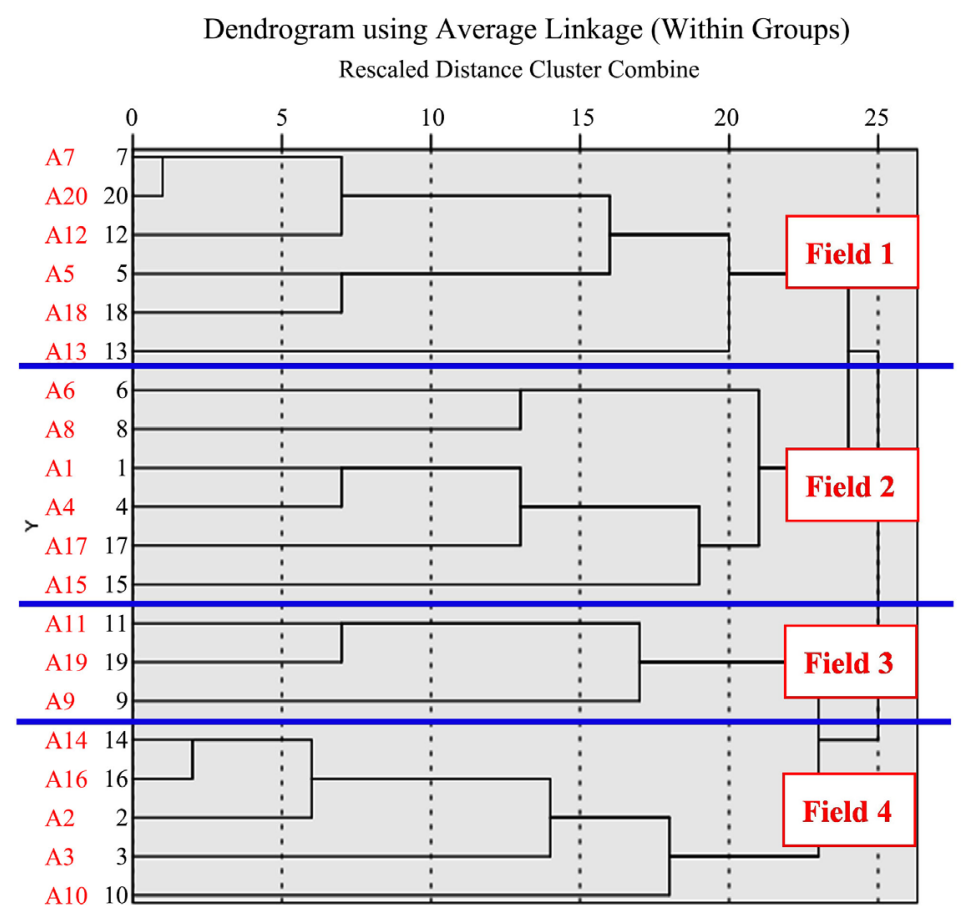

Figure 2. Core literacy high frequency keyword clustering tree figure. Field 1: A7. dialogue. A20. understand. A12. democratic equality. A5. intersubjectivity. A18. subjectivity. A13. knowledge-based view. Field 2: A6. student learning. A8. primary and secondary school students. A1. Teacher-student Relationship. A4. interpersonal relationship. A17. teacher. A15. concern. Field 3: A11. postgraduate. A19. alienation. A9. refactoring. Field 4: A14. ideological and political theory course. A16. university student. A2. harmonious teacher-student relationship. A3. college teacher-student relationship. A10. contact.

\subsection{Multidimensional Scaling Analysis of High Frequency Keywords}

Multidimensional scaling (MDS) is a statistical method of mathematical operations that mines deeper structures within data. It shows a two-dimensional coordinate drawn with centripetal and density parameters that can be used to generalize the structure of a domain or subdomain [11]. The high-frequency keyword dissimilarity matrix is imported into SPSS 19.0 statistical software, and the scatter plot of Euclidean distance model in multidimensional scale analysis is used. Combined with systematic cluster analysis results, the knowledge mapping of hot topics in teacher-student relationship research is drawn, as shown in Figure 3. According to the systematic cluster analysis results and multidimensional scaling analysis results of high-frequency keywords, refer to the relevant literature on teacher-student relationship research, and ask experts in the field of education to summarize the four major thematic areas of teacher-student relationship research: theoretical research and cognition of teacher-student relations (Field 1), the relationship between teacher-student relationship and student learning (Field 2), alienation and reconstruction of postgraduate teacher-student relations (Field 3), research on harmonious teacher-student relations in ideological and political theory course for college students (Field 4). 


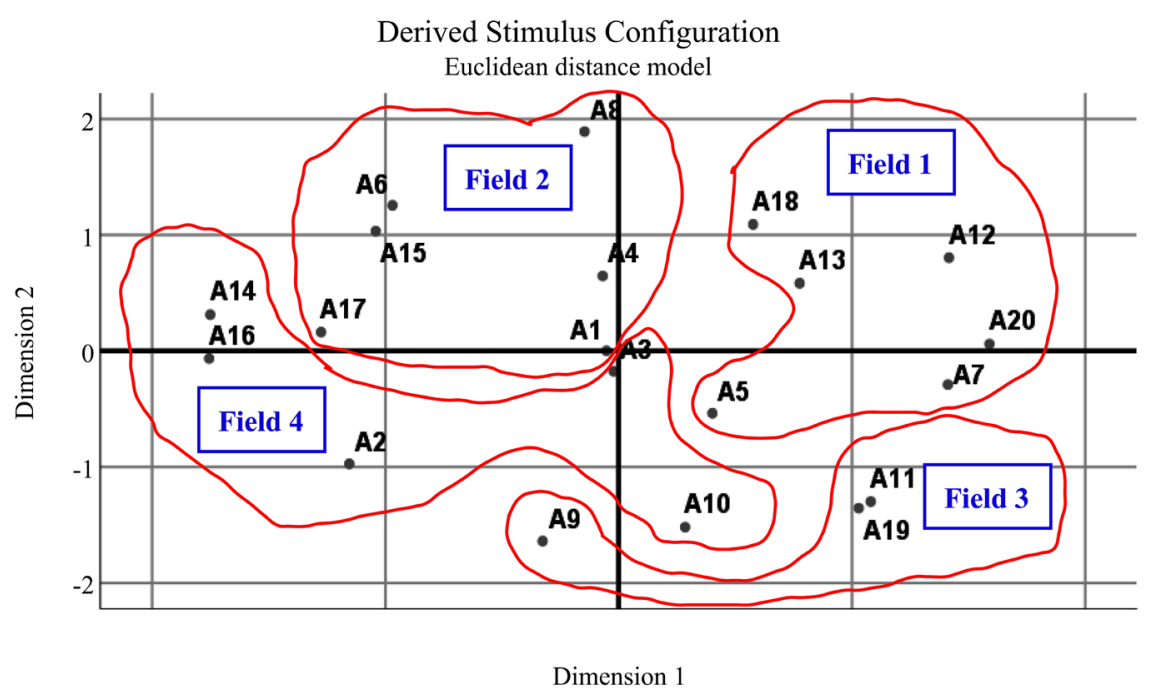

Figure 3. Core literacy research hot spot knowledge map. Field 1: A7. dialogue. A20. understand. A12. democratic equality. A5. intersubjectivity. A18. subjectivity. A13. knowledge-based view. Field 2: A6. student learning. A8. primary and secondary school students. A1. Teacher-student Relationship. A4. interpersonal relationship. A17. teacher. A15. concern. Field 3: A11. postgraduate. A19. alienation. A9. refactoring. Field 4: A14. ideological and political theory course. A16. university student. A2. harmonious teacher-student relationship. A3. college teacher-student relationship. A10. contact.

Field 1 mainly focuses on theoretical research and cognition of teacher-student relations, including 6 key words: dialogue, understand, democratic equality, intersubjectivity, subjectivity, knowledge-based view. In this field, "interalfred" is closer to the center, indicating that in the past 15 years, the research on teacher-student relationship mainly tends to be the relationship between subjects [12] [13]. The relationship between teachers and students is democratic equality, and teachers are chief among equals [14].

Field 2 mainly focuses on the relationship between teacher-student relationship and student learning, including 6 key words: student learning, primary and secondary school students, teacher-student relationship, interpersonal relationship, teacher, concern. As is known to all, teacher-student relationship, as a special interpersonal relationship, is an indispensable link in educational and teaching activities, and is also an important factor affecting teaching efficiency. In terms of higher education, Chinese scholars Ma, L., Jiang, P. P. et al. believe that teacher-student relationship is highly correlated with college students' learning engagement [5]. Li, B. S. believe that there is a certain correlation between teacher-student relationship and students' learning motivation [15]. Based on the perspective of new media, Shao, M. Y. and Ji, Y. P. et al. believe that mobile media influences the authority, teaching effect and teaching emotion of college teachers, etc [16]. In terms of basic education, Zou, H. et al. found that the teacher-student relationship with intimacy type, general type and conflict type has significant differences in middle school students' academic behaviors [17]. Chinese scholars Yang, J. P. et al. believe that teacher-student relationship has a 
significant impact on the learning psychology of primary school students and can predict their academic achievements [4]. Zhang, B. G. et al. believe that intimacy, dependence and conflict teacher-student relationship are significantly positively correlated with academic performance, with significant differences in conflict [18]. Li, X. Q. et al. believe that the self-esteem of floating children is significantly correlated with academic behavior and all dimensions of teacher-student relationship, and the teacher-student relationship can significantly predict the self-esteem development level of floating children [19]. It can be seen that the teacher-student relationship has a great impact on students' learning psychology. It is worth mentioning that after Learning to Care: Another Model of Education (Educational Science Publishing House) was published in 2003 by American Nel Noddings, the teacher-student relationship based on the theory of concern gradually became a new research hotspot. For example, Yang, S. P. puts forward that the key to building a harmonious teacher-student relationship lies in establishing a caring relationship between teachers and students [20]. Li, Q. F. and Zhou, F. X. believe that caring teacher-student relationship, characterized by relational, non-utilitarian and emotional nature, is the key to establishing the "life connection" between teachers and students, and the essential requirement of teacher-student relationship [21].

Field 3 mainly focuses on alienation and reconstruction of postgraduate teacher-student relations, including 3 key words: postgraduate, alienation, refactoring. As we know, the relationship between tutor and graduate student in graduate education is the most basic teacher-student relationship. According to the key words in Field 3, scholars begin to pay attention to the teacher-student relationship among graduate students, reveal the existing problems in the current teacher-student relationship, and propose corresponding solutions. For example, He, Z. J. et al. believe that the transfer of knowledge forms leads to the alienation of teacher-student relationship. They maintain that based on "Humanism" educational philosophy, with "Intersubjectivity" as the connotation, with the democratic and equal teacher-student relationship as the basic feature, and with the guiding relationship as the carrier, a new teacher-student relationship can be established to alleviate many contradictions and problems between tutors and graduate students [22]. Based on Marx's Alienated Labor Theory, Zhao, X. H. examines the external representation of teacher-student relationship alienation in graduate education: "Guidance Relations" is alienated to "Industrial Relations", "Communication Relations" to "Control Relationship", "Cooperative Relationship" to "Production Relations", and "Mutual Relationship" to "Conflict Relations". He also put forward the solution: give full play to the function of academic community between teachers and students, and rebuild the academic spirit of rational and truth-seeking; To build an equal dialogue mechanism and optimize the training process of graduate students; Strengthen the management of scientific research achievements of teachers and students and construct a reasonable evaluation and incentive mechanism [23]. 
Field 4 mainly focuses on research on harmonious teacher-student relations in ideological and political theory course for college students, including 5 key words: ideological and political theory course, university student, harmonious teacher-student relationship, college teacher-student relationship, contact. In this field, the teacher-student relationship in universities is close to the center, which indicates that Chinese scholars have focused on the research field of teacher-student relationship in universities in recent 15 years. Especially the construction of harmonious teacher-student relationship in ideological and political theory courses in colleges and universities. $\mathrm{Wu}, \mathrm{Y}$. J. put forward the idea of building a harmonious relationship between teachers and students to promote and deepen the effectiveness of Ideological and political theory teaching in Colleges and universities [24]. Ma, C. and Lou, S. H. put forward that the teacher-student relationship in ideological and political theory course of college students is a special social communication relationship based on teaching activities, which needs to adhere to the basic communication principles of equality, human nature, education and openness [25].

\section{Conclusion and Prospects}

In conclusion, through literature metrology and knowledge mapping analysis, it is more intuitively shown that the research on teacher-student relationship in China in the past 15 years mainly focuses on two main lines and four major fields. The two main lines are theoretical research and quantitative research on teacher-student relationship, four research fields: theoretical research and cognition of teacher-student relations, the relationship between teacher-student relationship and student learning, alienation and reconstruction of postgraduate teacher-student relations, research on harmonious teacher-student relations in ideological and political theory course for college students. However, due to various reasons, the conclusions of this study only provide data support and research reference for the teacher-student relationship research in the past 15 years, and more accurate research results also need scholars to mine the data more fully from multiple perspectives. We expect more and more researchers of teacher-student relationship to participate in the mapping of knowledge maps of teacher-student relationship research.

\section{Conflicts of Interest}

The author declares no conflicts of interest regarding the publication of this paper.

\section{References}

[1] Leavitt, H.J. (1958) Some Effects of Certain Communication Patens on Group Performance. Journal of Abnormal Psychology, 46, 38-50. https://doi.org/10.1037/h0057189

[2] Wang, X.D. (2000) A Study on the Relations between Teachers and Students Abroad. Hainan Publishing House, Hainan, 79. 
[3] Chen, K.X. (2001) Introduction to Educational Sociology. Taiwan Normal University Bookstore Co., Ltd., Taiwan, 157.

[4] Yang, J.P. and Gao, L. (2005) The Investigation and Research on the Current Situation of the Study Psychology and Teacher-Student Relationship of Primary School Students. Educational Research, 26, 63-68. http://www.cqvip.com/QK/96925X/200501/11709597.html

[5] Ma, L., Jiang, P.P. and Yang, R. (2017) Research on the Influence of Teacher-Student Relationship on College Students' Learning Engagement-Based on the Survey Data of Beijing Municipal Universities. Studies in Ideological Education, No. 7, 121-124. http://www.cqvip.com/QK/81875X/201707/672893975.html

[6] Yu, X.M., Zhao, J.R. and Wu, X. (2017) Investigation and Research on the Status Quo and Influence of Postgraduate Teacher-Student Relationship in Colleges-Based on Empirical Analysis of Three Universities. Journal of Tianjin University (Social Sciences), 19, 157-161. http://www.cqvip.com/QK/81472X/201702/671535575.html

[7] Cui, L., Liu, W., Yan, L., Zhang, H., Hou, Y.F., Huang, Y.N. and Zhang, H. (2008) Development of a Text Mining System Based on the Co-Occurrence of Bibliographic Items in Literature Databases. Data Analysis and Knowledge Discovery, 8, 70-75.

[8] Yao, Q.H., Wu, Y.N., Li, S., Li, Y.B. and Zheng, H.L. (2016) Analysis of Flipped Classroom Research Using Keywords Clustering. E-Education Research, 7, 106.

[9] Guo, W.B., Fang, J.M. and Chen, Q.Z. (2012) Chinese Autism: A Research Based on an Analysis of Common Keywords in Literature. Journal of Northwest Normal University (Social Sciences), 49, 128-132.

[10] Zhong, W.J., Li, J. and Yang, X.M. (2008) The Research of Co-Word Analysis (3) - The Principle and Characteristics of the Co-Word Cluster Analysis. Journal of Information, 7, 118.

[11] Guo, W.B. and Yu, S.W. (2014) Hot Knowledge Map of Distance Education Research in China-Keyword Co-Word Analysis Based on 3170 Master's and Doctoral Dissertation. E-Education Research, 2, 49.

[12] Yu, X.Y. (2004) Intersubjectivity: A New Perspective to Understand Teacher-Student Relationship. Contemporary Educational Science, No. 19, 10-12. http://www.cqvip.com/QK/82379A/200419/11063097.html

[13] Yan, L.S. (2008) A Study of Teacher-Student Relationship from the Perspective of Postmodern Education. Journal of Educational Science of Hunan Normal University, 7, 54-57.

[14] Li, F. (2004) An Inquiry into the Concepts of Post-Modern Teaching. Educational Research, 25, 35-40. http://www.cqvip.com/QK/96925X/200411/11307716.html

[15] Li, B.S. (2014) Study on the Correlation between Learning Motivation, Values and Teacher-Student Relationship of College Students in Guangzhou Area. Higher Education Exploration, No. 5, 178-184. http://www.cnki.com.cn/Article/CJFDTOTAL-GJTA201405038.htm

[16] Shao, M.Y. and Ji, Y.P. (2016) The Influence of College Students' Learning Style on the Relationship between Teachers and Students in the Era of Mobile Media. Ideological \& Theoretical Education, 5, 108.

[17] Zou, H. and Li, C.N. (2009) Relationships of Personality, Learning Behaviors and Teacher-Student Relationships in Secondary School Students. Journal of Beijing Normal University (Social Science), 1, 59.

[18] Zhang, B.G. and Jiang, T. (2009) A Correlation Analysis of Teacher-Student Rela- 
tionship and Academic Achievement in Junior High Schools. Psychological Science, 4, 1015-1017.

[19] Li, X.Q., Zou, H., Wang, R.M. and Dou, D.H. (2008) The Developmental Characteristics of Temporary Migrant Children's Self-Esteem and Its Relation to Learning Behavior and Teacher-Student Relationship in Beijing. Psychological Science, 31, 909.

[20] Yang, S.P. (2009) On Reconstructing Teacher-Student Relationship in the Visual Field of Caring. Education Science, 3, 52.

[21] Li, Q.F. and Zhou, F.X. (2018) Teacher-Student Relationship and Its Construction from the Perspective of Care Theory. Theory and Practice of Education, 38, 32-35. http://www.wanfangdata.com.cn/details/detail.do?_type=perio\&id=jyllysj201834008

[22] He, Z.J., Li, L. and Zhou, Z. (2007) On the Dissimilation and Rebuild of Student and Teacher Relationship in Postgraduate Education. Studies in Foreign Education, 34, 40-43. http://www.cnki.com.cn/Article/CJFDTOTAL-WGJY200706010.htm

[23] Zhao, X.H. (2018) The External Representation of the Alienation of Teacher-Student Relationship and Its Generating Logic in Postgraduate Education-On the Perspective of Marx's Alienated Labor Theory. Modern Education Science, 3, 74.

[24] Wu, Y.J. (2009) On the Construction of Harmonious Teacher-Student Relationship in the Teaching of Ideological and Political Theory Courses. The Party Building and Ideological Education in Schools, 35, 36-37. http://www.cnki.com.cn/Article/CJFDTOTAL-XXDJ200935016.htm

[25] Ma, C. and Lou, S.H. (2017) An Analysis of the Communication Principles of the Harmonious Relationship between Teachers and Students in College Students' Ideological and Political Theory Courses. Ideological and Political Education Research, 1,71 . 